\title{
Fertilizantes foliares, regulador de crescimento e glyphosate no crescimento vegetativo da soja tolerante ao glyphosate
}

\author{
Gabriela Gayoso da Cruz ${ }^{1}$, Luisa Carolina Baccin ${ }^{1}$, Leandro Paiola Albrecht ${ }^{1}$, Alfredo Júnior Paiola Albrecht ${ }^{1}$, \\ Fábio Henrique Krenchinski \\ ${ }^{1}$ Universidade Federal do Paraná - UFPR, Setor Palotina, PR. Universidade Estadual Paulista - UNESP, Botucatu, SP. E- \\ mail: luisa.cbio@gmail.com
}

\section{Resumo}

O trabalho teve por objetivo avaliar o desempenho da soja submetida a doses de glyphosate em associações com fertilizantes foliares e regulador de crescimento vegetal, visando o processo de reversão do efeito fitotóxico na soja RR2. O experimento foi conduzido entre novembro de 2015 e janeiro de 2016 , em casa de vegetação situada na Universidade Federal do Paraná - Setor Palotina. Utilizou-se a cultivar Monsoy 6210 IPRO $^{\circledR}$. As plantas foram submetidas a aplicação de glyphosate nas doses 0, 720, 1440, 2160 e 2880 g e.a. ha $^{-1}$ e doses de glyphosate em associação com os produtos: regulador de crescimento vegetal (cinetina 0,09 $\mathrm{g} \mathrm{L}^{-1}$, ácido giberélico 0,05 $\mathrm{g} \mathrm{L}^{-1}$ e ácido 4-indol-3-butílico 0,05 $\mathrm{g} \mathrm{L}^{-1}$ ) na dose $250 \mathrm{ml} \mathrm{ha}^{-1}$, manganês ( $\mathrm{Mn}$ na forma de um quelato de aminoácido, $62,5 \mathrm{~g} \mathrm{~L}^{-1}$ ) na dose de $1 \mathrm{~L}$, e o composto de aminoácidos (hidrolisado proteico, ácido fosfórico, hidróxido de potássio e água, $1 \mathrm{~L}$ ha $^{-1}$ ). $A$ aplicação foi realizada no estágio V4. Avaliou-se índice de clorofila, matéria seca de parte aérea e raiz, e sintomas de fitointoxicação na cultura. Os dados foram submetidos a análise de variância, submetidos ao teste de Tukey $(p \leq 0,05)$ e análise de regressão para o fator dose. Não foram observadas diferenças entre os tratamentos com fertilizantes e regulador vegetal e o herbicida. Os sintomas de fitointoxicação da cultura e os níveis de clorofila foram proporcionais ao aumento de dose do herbicida, porém houve uma recuperação da cultura após 35 DAA. Para matéria seca de raiz e parte aérea das plantas, não foi observada diferença entre os manejos de reversão da fitointoxicação. Trabalhos à campo são necessários para constatação de efeitos dos produtos na fisiologia das plantas visando um possível incremento de produtividade.

Palavras-chave: Glicine max; Herbicidas; Transgênicos; Yellow flashing.

\section{Influence of foliar fertilizers, growth regulator and glyphosate on vegetative growth of glyphosate tolerant soybean}

\begin{abstract}
The objective of this work is to evaluate the performance of soybean submitted to glyphosate doses in association with foliar fertilizers and plant growth regulator, aiming the reversal of phytotoxic effect in RR2 soybean. The experiment was conducted between November 2015 and January 2016, in a greenhouse located at the Federal University of Paraná - Setor Palotina. Monsoy 6210 IPRO ${ }^{\circledR}$ was used. The plants were submitted to glyphosate application at 0, 720, 1440, 2160 and $2880 \mathrm{~g}$ a. e ha ${ }^{-1}$ and glyphosate in association with the products: plant growth regulator (kinetin $0.09 \mathrm{~g} \mathrm{L-1,} \mathrm{gibberellic} \mathrm{acid).} 0.05 \mathrm{~g}$ L-1 and 4-indol-3-butyl acid $0.05 \mathrm{~g} \mathrm{~L}-1$ ) at the dose $250 \mathrm{ml} \mathrm{ha}^{-1}$, manganese (Mn as an aminoacid chelate, $62.5 \mathrm{~g} \mathrm{~L}^{-1}$ ) at a dose of $1 \mathrm{~L}$, and the aminoacid compound (protein hydrolysate, phosphoric acid, potassium hydroxide and water, $1 \mathrm{~L}^{-}$ $\left.{ }^{1}\right)$. The application was performed at stage V4. Chlorophyll index shoot and root dry matter, and phytointoxication symptoms in the crop were evaluated. Data were subjected to analysis of variance, Tukey test $(p \leq 0.05)$ and regression analysis for the dose factor. No differences were observed between fertilizer and plant regulator treatments and herbicide. Symptoms of crop phytointoxication and chlorophyll levels were proportional to herbicide dose increase, but there was a recovery of culture after 35 DAA. For root and shoot dry matter, no difference was observed between the phytointoxication reversal management. Field work is necessary to verify the effects of products on plant physiology aiming at a possible increase of productivity.
\end{abstract}

Keywords: Glycine max; Herbicide; Transgenic crops; Yellow flashing. 


\section{Introdução}

A tolerância da soja ao glyphosate representou uma enorme conquista tecnológica para o setor agrícola, tornando-se uma excelente ferramenta para o produtor devido aos inúmeros benefícios advindos dessa tecnologia (ALBRECHT et al., 2018). A soja geneticamente modificada foi criada com a finalidade de simplificar o manejo de plantas daninhas e diminuir o número de aplicações de herbicidas e inseticidas. Desde a introdução da tecnologia no país, dados do CIB (2018) apontam para um aumento de produção de soja equivalente a $287 \%$.

O glyphosate, herbicida não seletivo, é muito utilizado na agricultura devido ao seu amplo espectro de ação e fácil aplicação, além da viabilidade econômica. Este herbicida atua inibindo a enzima 5-enolpiruvil-shiquimato-3fosfato sintase (EPSPS), da rota do chiquimato, que leva à síntese dos aminoácidos aromáticos essenciais tirosina, fenilalanina e triptofano (SILVA et al., 2009; DVORANEN et al., 2008).

$\mathrm{O}$ intenso uso de soja transgênica, e consequentemente do glyphosate, levou a um mau gerenciamento da tecnologia, o tem diminuído a eficiência do herbicida contra algumas espécies invasoras, devido a seleção de biótipos de plantas daninhas resistentes, levando os produtores a utilizarem maiores doses do produto, resultando assim, em injurias visuais às plantas por fitointoxicação. De acordo com Zobiole et al. (2010) este sintoma observado na soja é conhecido como "Yellow flashing" ou também denominado como amarelecimento das folhas superiores.

A ocorrência desse amarelecimento tem levado muitos produtores ao uso intensivo de fertilizantes foliares como alternativa para amenizar ou suprir essa possível deficiência nutricional, sem, no entanto, haver necessariamente a recuperação da cultura (ZOBIOLE et al., 2011; FREITAS et al., 2018). Outra possibilidade de amenizar os efeitos do glyphosate que tem sido aventada é o uso de biorreguladores (BERTOLIN et al., 2010.)

Portanto, o presente trabalho teve como propósito avaliar a associação de fertilizantes foliares e regulador de crescimento ao herbicida glyphosate visando a redução dos efeitos de fitointoxicação da soja RR.

\section{Material e métodos}

O experimento foi realizado em casa de vegetação, no período de 11/2015 a 01/2016, na Universidade Federal do Paraná - Setor Palotina - PR. A cultivar utilizada foi a Monsoy 6210 IPRO $^{\circledR}$ de hábito de crescimento indeterminado e grupo de maturação 6.2 , cultivada em condições de temperatura de 20-25ㅇ, umidade relativa de $60 \%$, lâmina média de irrigação de $5 \mathrm{~mm} /$ dia e fotoperíodo de 12 horas.

0 delineamento experimental foi inteiramente casualizado em esquema fatorial $5 x$ 4 (doses $x$ manejos), com quatro repetições. 0 herbicida glyphosate em doses de 0, 720, 1440, 2160 e 2880 g e.a. ha ${ }^{-1}$ foi pulverizado em associação com os fertilizantes foliares e regulador de crescimento vegetal (ausente, Manganês Biometal ${ }^{\circledR}$, Protemax $^{\circledR}$ e Stimulate ${ }^{\circledR}$ ). Cada parcela experimental consistiu em um vaso de plástico de capacidade de $4 \mathrm{~L}$ de solo. $\mathrm{O}$ solo utilizado para o crescimento das plantas de soja é classificado como latossolo vermelho eutroférrico, de textura muito argilosa, com $61,25 \%$ de argila, $20 \%$ de areia e $18,75 \%$ de silte, apresentando $\mathrm{pH}$ em $\mathrm{CaCl}_{2}$ de 5,3, 13,46 $\mathrm{mg} \mathrm{dm}^{3}$ de $\mathrm{P}, 68,7 \%$ de saturação por bases e $31,48 \mathrm{~g} \mathrm{~kg}^{-1}$ de matéria orgânica. Dez sementes de soja tratadas com fipronil+piraclostrobina foram distribuídas homogeneamente sobre a superfície do solo e incorporadas até $3 \mathrm{~cm}$ de profundidade. Posteriormente, houve desbaste, mantendo-se duas plantas por vaso.

$O$ regulador de crescimento vegetal e os fertilizantes foliares utilizados no experimento foram Stimulate ${ }^{\circledast}\left(0,09 \mathrm{~g} \mathrm{~L}^{-1}\right.$ de cinetina, 0,05 $\mathrm{g} \mathrm{L}^{-1}$ ácido giberélico e $0,05 \mathrm{~g} \mathrm{~L}^{-1}$ de ácido 4-indol-3butílico); Manganês Biometal ${ }^{\otimes}\left(62,5 \mathrm{~g} \mathrm{~L}^{-1}\right.$ de manganês); e $\operatorname{Protemax}^{\circledR}$ (hidrolisado proteico, ácido fosfórico, hidróxido de potássio e água) de concentrações não identificadas na bula, nas formulações.

A aplicação foi realizada no estádio fenológico V4 da soja (quarto nó, ou terceira folha trifoliolada completamente expandida), com auxílio de um pulverizador costal pressurizado a $\mathrm{CO}_{2}$, equipado de barra com 4 pontas de pulverização, espaçadas de $0,5 \mathrm{~m}$, com volume de calda equivalente a $150 \mathrm{~L} \mathrm{ha}^{-1}$.

Para os possíveis sintomas de fitointoxicação foi atribuída uma nota visual aos 7, 14, 21, 28 e 35 dias após a aplicação (DAA), utilizando-se escala de 0 a $100 \%$, em que zero representa a ausência de sintomas e 100\% a 
morte das plantas (VELINI et al., 1995). Simultaneamente, realizou-se a medição do índice de clorofila, com auxílio de um aparelho Clorofilômetro ClorofiLOG ${ }^{\circledR}$ (Junior et al., 2012) antes da aplicação dos tratamentos e aos 7, 14, 21,28 e 35 DAA. As medições foram realizadas no terceiro trifólio totalmente expandido. No estádio fenológico R2 (florescimento pleno), as plantas foram fragmentadas em parte aérea e a raiz. Foi coletada toda a parte aérea (haste principal, ramos, folhas e flor) e raiz. Todo material vegetal foi levado para secagem em estufa a 65 드, até atingir massa constante.

Os dados foram submetidos à análise de variância univariada (ANOVA) pelo teste $F$ $(p<0,05)$, e quando detectado efeito significativo, realizou-se a análise de regressão para o fator dose $(p<0,05)$ e a comparação de médias pelo teste de Tukey $(p<0,05)$ para o fator manejos. Todas as análises estatísticas foram realizadas no programa computacional SISVAR ${ }^{\circledR}$. A transformação de dados por raiz quadrada de $Y+$
1,0 - SQRT $(Y+1,0)$ foi utilizada para as variáveis de fitointoxicação e massa.

\section{Resultados e discussão}

De modo geral, aos 7 e 14 DAA foram registradas maiores escores de fitointoxicação, mas não causaram a morte das plantas (Tabela 1). A associação do aminoácido + glyphosate causou sintomas mais pronunciados de fitointoxicação até 21DAA, contrário as associação de glyphosate + manganês $e$ glyphosate + regulador de crescimento, demonstrando que esta associação de produtos é inviável visando redução de fitointoxicação da cultura. O sintoma observado após aplicação do herbicida foi o amarelecimento das folhas do ponteiro na planta, sempre nos folíolos mais novos.

Observa-se que após os 28 DAA houve atenuação dos sintomas de amarelecimento nos folíolos novos das plantas, não diferindo a aplicação isolada do herbicida das associações em todas as avaliações.

Tabela 1. Notas visuais de fitointoxicação em soja M6210IPRO sob aplicação de associação de glyphosate com fertilizantes foliares e regulador de crescimento vegetal. Palotina - PR, 2015/2016.

\begin{tabular}{cccccc}
\hline \multirow{2}{*}{ Manejo } & \multicolumn{6}{c}{ Fitointoxicação } \\
& 7 DAA & 14 DAA & 21 DAA & 28 DAA & 35 DAA \\
\hline Gly & $12,90 \mathrm{ab}$ & $11,80 \mathrm{ab}$ & $10,45 \mathrm{ab}$ & $5,25 \mathrm{a}$ & $2,20 \mathrm{a}$ \\
Gly + Amin & $14,20 \mathrm{~b}$ & $13,10 \mathrm{~b}$ & $11,30 \mathrm{~b}$ & $5,15 \mathrm{a}$ & $2,30 \mathrm{a}$ \\
Gly + Mang & $10,95 \mathrm{a}$ & $10,30 \mathrm{a}$ & $9,05 \mathrm{a}$ & $4,30 \mathrm{a}$ & $1,45 \mathrm{a}$ \\
Gly+ Reg & $12,95 \mathrm{ab}$ & $10,95 \mathrm{a}$ & $9,35 \mathrm{a}$ & $3,85 \mathrm{a}$ & $1,55 \mathrm{a}$ \\
\hline CV \% & 9,55 & 10,26 & 9,81 & 19,53 & 24,94 \\
DMS & 2,08 & 2,09 & 1,73 & 1,65 & 1,10 \\
Média Geral & 12,75 & 11,54 & 10,03 & 4,63 & 1,87 \\
\hline
\end{tabular}

Médias seguidas de letras iguais na coluna não diferem significativamente $(p<0,05)$ pelo teste de Tukey. Gly: Glyphosate; Gly+Amin: Glyphosate + aminoácido; Gly + Mang: Glyphosate + Manganês; Gly+Reg: Glyphosate + regulador de crescimento vegetal.

Em estudos conduzidos com aplicação de glyphosate em soja RR, Zobiole et al. (2009) apontam que a aplicação de herbicida leva a uma redução nos teores foliares de macro e micronutrientes em soja. Merotto et al. (2015) cita que após a aplicação de herbicida, a planta sofre estresse que leva a imobilização de cátions divalentes, como o ferro e o manganês, isso se dá pela capacidade do herbicida em quelar cátions devido sua característica química.

A soja apresenta capacidade de recuperação deste sintoma, corroborando com dados de Krenchinski et al. (2017) no qual os sintomas de fitointoxicação também foram significativamente reduzidos após os 28 dias após a aplicação. Os autores citam que a fitointoxicação é proporcional ao aumento de dose, porém com o passar do tempo as plantas têm a capacidade de detoxificação dos efeitos do herbicida.

Com relação às doses de glyphosate, foi verificado efeito linear para a fitointoxicação (Figura 1). Portanto, à medida que a dose de glyphosate foi aumentada, maiores foram os sintomas de fitointoxicação às plantas de soja.

Alguns trabalhos que mostram que além da injúria visual, podem haver reduções nos índices e clorofila, teores nutricionais, qualidade de 
sementes, e até em produtividade com a aplicação de doses elevadas e aplicações mais tardias (a partir de V6 ou no período reprodutivo) do glyphosate em soja transgênica (ALBRECHT et al., 2018; ALBRECHT et al., 2011; CESCO et al., 2018). Além da perda de biomassa, redução na eficiência do uso de água pelas plantas e redução nos teores de macro e micronutrientes (ZOBIOLE et al., 2009; ZOBIOLE et al., 2010).

Figura 1. Notas visuais de fitointoxicação em soja M6210IPRO sob aplicação de doses de glyphosate. Palotina - PR, 2015/2016.

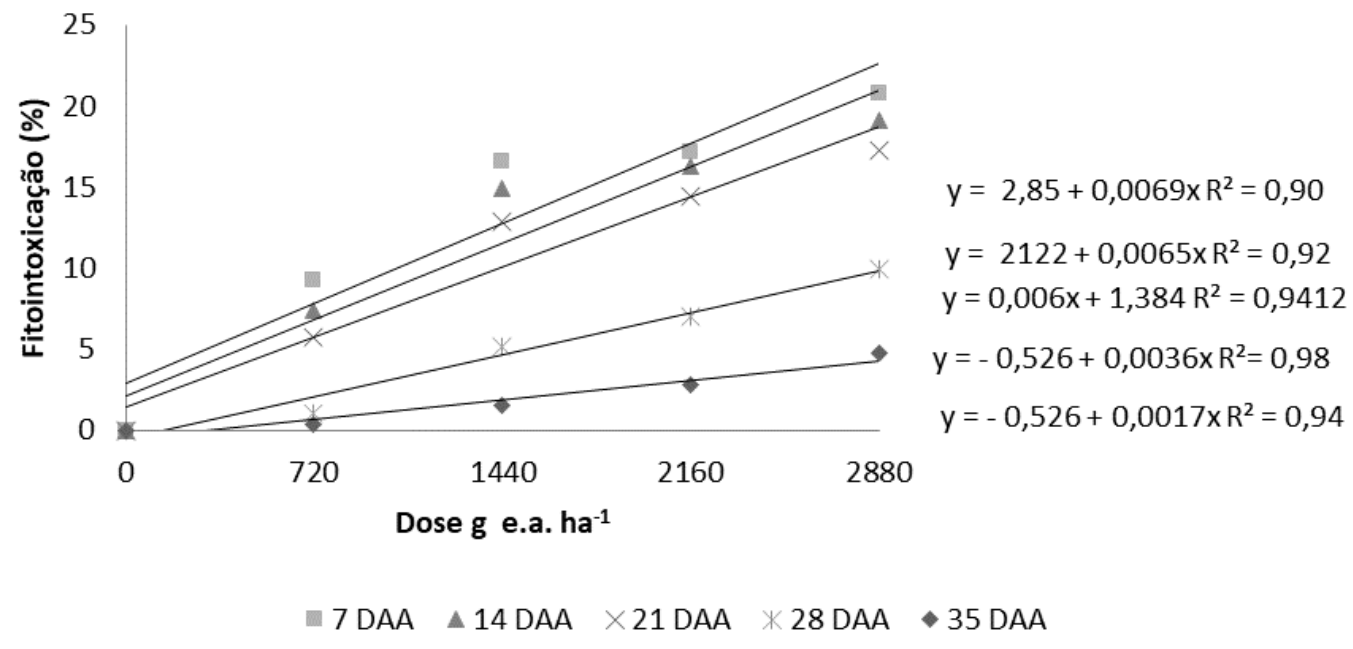

O índice de clorofila, massa seca de parte aérea e massa seca de raiz não foram influenciadas pela associação de glyphosate a fertilizantes foliares e regulador de crescimento (Tabelas 2 e 3).

Tabela 2. Índice de clorofila em soja M6210IPRO sob aplicação de associação de glyphosate com fertilizantes foliares e regulador de crescimento vegetal. Palotina - PR, 2015/2016.

\begin{tabular}{ccccccc}
\hline Manejo & \multicolumn{7}{c}{ Clorofila $^{\text {Ns }}$} \\
& 0 DAA & 7_DAA & 14_DAA & 21_DAA & 28_DAA & 35_DAA \\
\hline Gly & 39,37 & 28,10 & 20,28 & 26,55 & 28,64 & 30,75 \\
Gly + Amin & 40,86 & 26,43 & 20,58 & 25,76 & 31,89 & 29,96 \\
Gly + Mang & 40,44 & 27,72 & 21,54 & 26,87 & 29,45 & 30,77 \\
Gly+ Reg & 39,78 & 27,71 & 20,81 & 26,79 & 29,61 & 29,52 \\
\hline CV \% & 6,67 & 22,07 & 8,97 & 9,59 & 13,46 & 9,16 \\
DMS & 2,23 & 5,07 & 1,56 & 2,12 & 3,36 & 2,31 \\
Média Geral & 40,11 & 27,49 & 20,8 & 26,49 & 29,9 & 30,25 \\
\hline Ns - Não significativo (p<0,05). Gly: Glyphosate; Gly+Amin: Glyphosate + aminoácido; Gly + Mang: Glyphosate + \\
Manganês; Gly+Reg: Glyphosate + regulador de crescimento vegetal.
\end{tabular}


Tabela 3. Matéria seca de parte aérea e raiz em soja M6210IPRO sob aplicação de associação de glyphosate com fertilizantes foliares e regulador de crescimento vegetal. Palotina - PR, 2015/2016.

\begin{tabular}{ccc}
\hline Manejo & MS Raiz $^{\text {Ns }}$ & MS Parte aérea $^{\text {Ns }}$ \\
\hline Gly & 6,43 & 141,30 \\
Gly + Amin & 4,83 & 136,25 \\
Gly + Mang & 6,76 & 142,70 \\
Gly + Reg & 5,73 & 146,30 \\
\hline CV \% & 25,66 & 11,11 \\
DMS & 3,12 & 26,38 \\
Média Geral & 5,94 & 141,63 \\
\hline
\end{tabular}

Ns - Não significativo $(p<0,05)$. Gly: Glyphosate; Gly+Amin: Glyphosate + aminoácido; Gly + Mang: Glyphosate + Manganês; Gly+Reg: Glyphosate + regulador de crescimento vegetal.

Para as variáveis índice de clorofila, massa seca de parte aérea e massa seca de raiz, observou-se diferença significativa apenas para o fator dose $(p<0,05)$. O índice de clorofila (Figura 2) foi menor aos 14 e 21 DAA, o que pode estar relacionado com os maiores níveis de fitointoxicação. Segundo Zobiole et al. (2010), plantas de soja que receberam aplicação de glyphosate possuem menor concentração de clorofila, que provavelmente ocorre devido ao menor teor de nutrientes, especialmente ao $\mathrm{Mn}$ e $\mathrm{Mg}$, que atuam na produção e funcionalidade da clorofila.

Figura 2. Índice de clorofila em soja M6210IPRO sob aplicação de doses de glyphosate. Palotina - PR, 2015/2016.

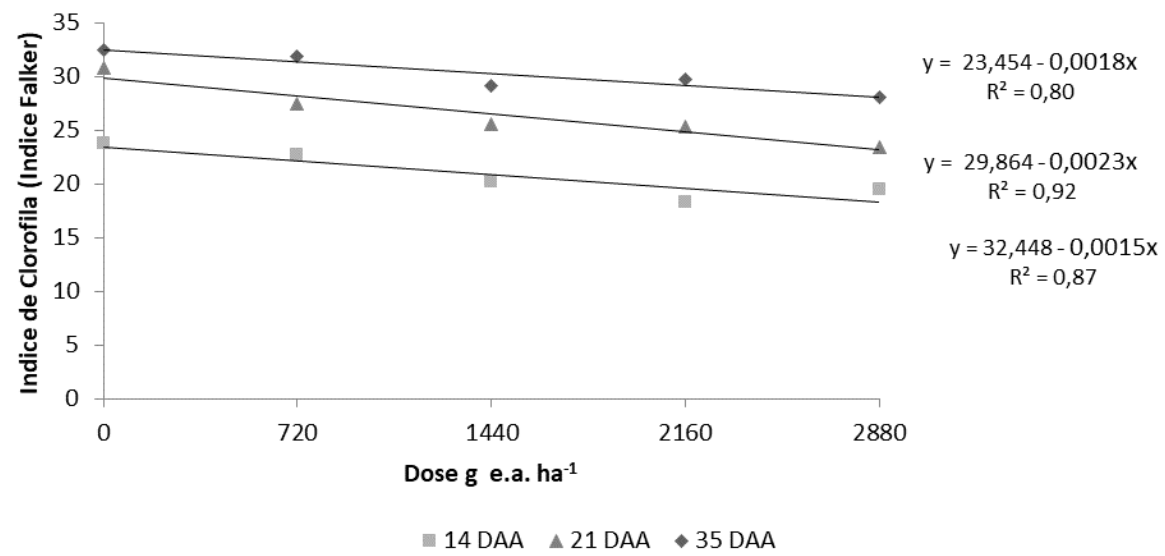

Contudo, aos 35 dias observa-se um aumento no teor de clorofila das plantas, isso pode se dar ao fato de que a planta já tenha se recuperado do estresse sofrido após a aplicação do herbicida, conforme observado por Zobiole et al. (2010), após a aplicação do glyphosate, há uma significativa redução do índice de clorofila, e com o decorrer dos dias tal efeito apresenta-se menos pronunciado. Este efeito de recuperação está relacionado ao aumento dos teores dos nutrientes que são quelados após aplicação do herbicida ( $\mathrm{Mg}$ e $\mathrm{Mn}$ ) retomando gradativamente a produção de clorofila na planta.

Conforme o aumento das doses de glyphosate houve a redução da matéria seca de parte aérea e raiz (Figura 3 e 4). Mesmo levando em consideração que altas doses de glyphosate, não são recomendadas oficialmente para aplicação em pós emergência, sabe-se que na prática eventualmente são utilizadas doses maiores desse produto (ALBRECHT, 2014). Tal redução de biomassa observada possivelmente se deve ao fato destas doses terem provocado maiores injúrias nas folhas, órgão fonte no desenvolvimento da cultura, responsável pela produção dos fotoassimilados. Segundo Serra et al. (2011) a planta sofre um estresse fisiológico logo após a aplicação de glyphosate, que mesmo se recuperando posteriormente, provoca menor produção de massa seca de parte aérea.

De acordo com Feng et al. (1999); Hetherington et al. (1999) o glyphosate é 
rapidamente translocado para os tecidos mais jovens de crescimento de raízes e tecidos onde podem acumular em concentrações milimolares, após a aplicação foliar, podendo ocasionar assim um leve redução na massa seca de raiz, contudo sem comprometer o desenvolvimento da planta.

Figura 3. Massa da matéria seca de parte aérea em soja M6210IPRO sob aplicação de doses de glyphosate. Palotina - PR, 2015/2016.

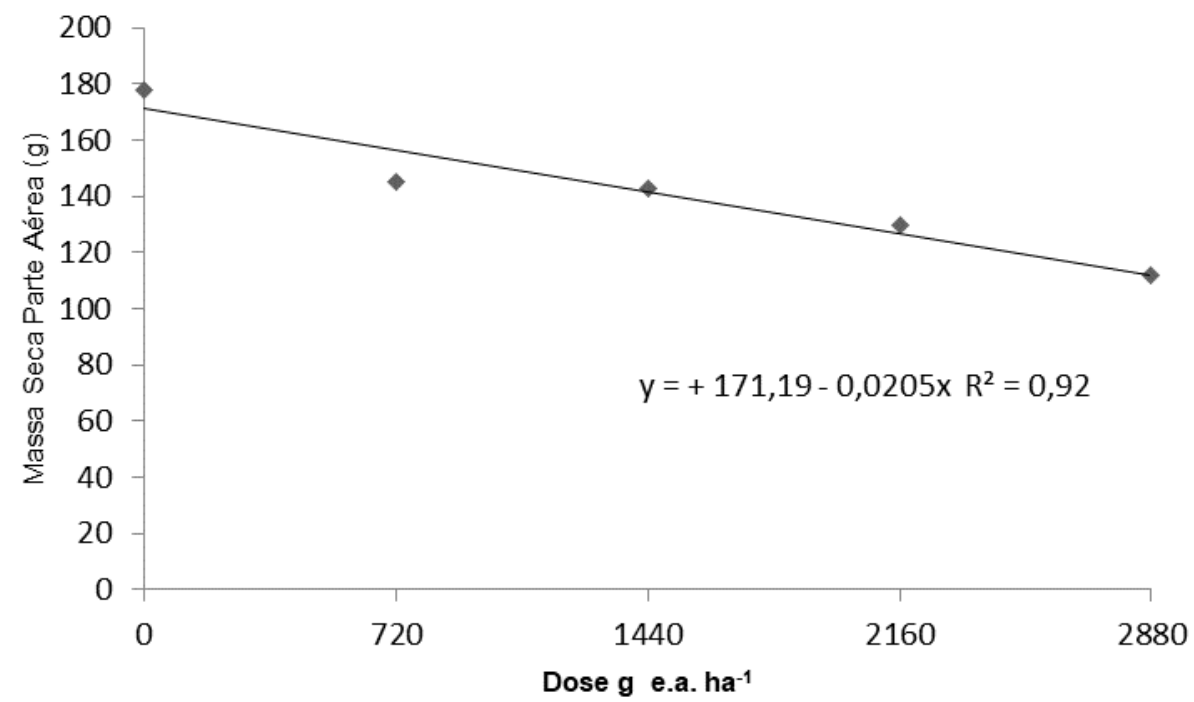

Figura 4. Massa da matéria seca de raiz em soja M6210IPRO sob aplicação de doses de glyphosate. Palotina $-P R, 2015 / 2016$.

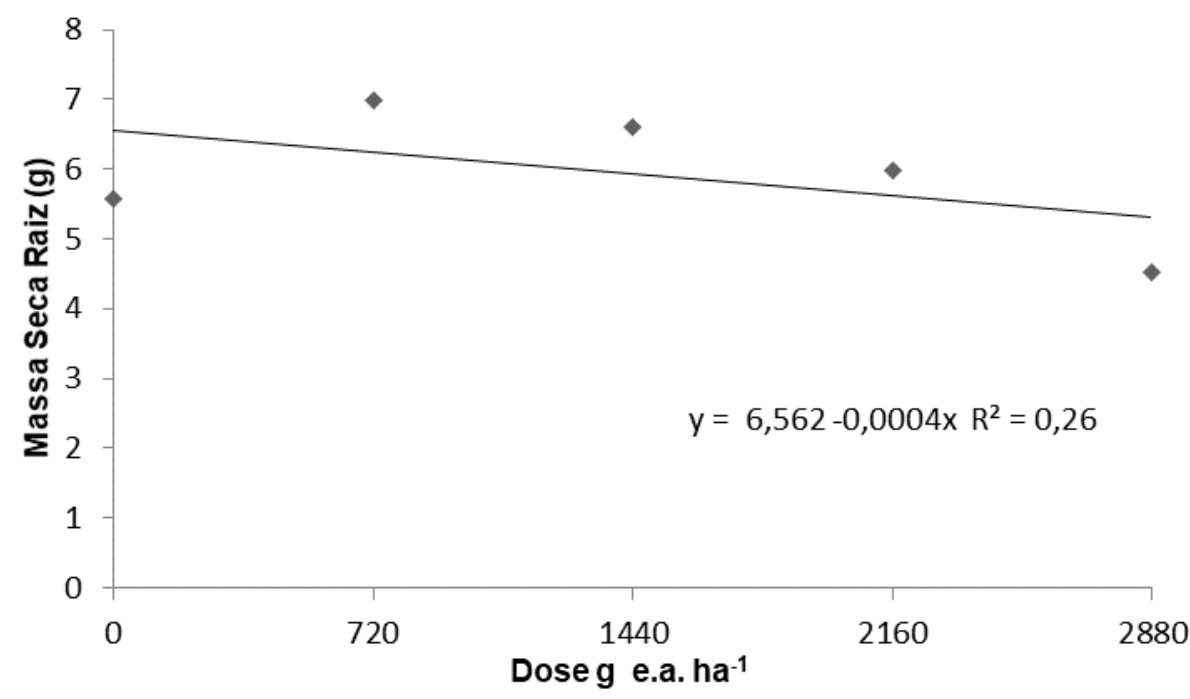

Os tratamentos contendo manganês e biorregulador não diferiram do tratamento com aminoácido no processo de reversão da fitointoxicação, e ao decorrer dos dias, independente do produto utilizado a planta mostra-se recuperada de tal efeito. Freitas et al. (2018) avaliando o desempenho da soja submetida a aplicação do herbicida glyphosate observou incremento de produtividade após o tratamento com fertilizante foliar (contendo manganês na formulação) em associação com o herbicida. Do mesmo modo os autores não observaram diferença significativa quanto a comprimento de parte aérea e de raiz das plantas, corroborando com dados obtidos no presente estudo.

Outras pesquisas realizadas com a aplicação de fertilizante foliar a base de manganês também observaram um incremento da produtividade da soja (SANTOS et al., 2015), bem como a avaliação da aplicação de reguladores vegetais (BERTOLIN, 2010). Tais pesquisas apontam que a recuperação da cultura após o estresse causado pelo herbicida pode ser afetada pela aplicação exógena de 
produtos visando a atenuação dos sintomas, seja através da reposição dos nutrientes que ficam temporariamente indisponíveis (ou quelados) após a aplicação do herbicida ou por afetar o balanço hormonal de forma positiva promovendo crescimento da planta.

Nas condições do presente trabalho, para a cultivar estudada, foi observado que não há diferença quanto a aplicação do herbicida isolado da aplicação do herbicida associado com fertilizantes foliares e regulador de crescimento no processo de reversão de fitointoxicação levando em consideração a análise visual de fitointoxicação e os teores de clorofila. Observase que a cultura apresenta capacidade de recuperação dos sintomas após aplicação do herbicida cerca de 28 dias após a aplicação, porém mais trabalhos se fazem necessários visando avaliar o comportamento das tecnologias à campo, no resultado de produtividade final, com o intuito de avaliar a campo outros genótipos, locais e anos/safra de cultivo, a fim de reconsiderar o potencial de utilização do uso de reversores de fitointoxicação no manejo com o glyphosate. Tais resultados auxiliam na tomada de decisão, além de constituírem uma importante ferramenta disponível aos produtores no manejo da lavoura.

\section{Agradecimentos}

CNPQ pela concessão de bolsas, Universidade Federal do Paraná e equipe Supra Pesquisa.

\section{Referências}

ALBRECHT, A. J. P.; ALBRECHT, L. P.; BARROSO, A. A. M.; CESCO, V. J. S.; KRENCHINSKI, F. H.; SILVA, A. F. M.; VICTORIA FILHO, R. Glyphosate tolerant soybean response to different management systems. Journal of Agricultural Science, v.10, n.1, p.204-216, 2018. https://doi.org/10.5539/jas.v10n1p204

ALBRECHT, L. P.; ALBRECHT, A. J. P.; BRACCINI, A. L.; OLIVEIRA JR., R. S.; ZOBIOLE, L. H. S.; ÁVILA, M. $R$. The role of glyphosate in RR soybean production and seed quality. Planta Daninha, v.32, n.2, p.401-407, 2014. http://dx.doi.org/10.1590/S0100-

\section{8}

ALBRECHT, L.P.; BARBOSA, A.P.; SILVA, A.F.M.; MENDES, M.A.; MARASCHISILVA, L.M.; ALBRECHT, A.J.P. Desempenho da soja Roundup Ready sob aplicação de glyphosate em diferentes estádios. Planta Daninha, v. 29, n. 3, p. 585-590, $2011 . \quad$ http://dx.doi.org/10.1590/S0100$\underline{83582011000300012}$

BERTOLIN, D.C.; SÁ, M.E.; ARF, O.; JUNIOR, E.F.; COLOMBO, A.S.; CARVALHO, F.L.B.M. Aumento da produtividade de soja com a aplicação de bioestimulantes. Bragantia, v. 69, n.2, p. 339-347, 2010. http://dx.doi.org/10.1590/S000687052010000200011

CESCO, V.J.S.; KRENCHINSKI, F.H.; RODRIGUES, D.M.; NARDI, R.; ALBRECHT, A.J.P.; ALBRECHT, L.P. Agronomic Performance of Intacta RR2 Soybean Submitted to Doses of Glyphosate. Planta Daninha, v.36, 2018. https://dx.doi.org/10.1590/s0100$\underline{83582018360100109}$

CIB. 20 anos de transgênicos: benefícios ambientais, econômicos e sociais no Brasil. Resumo executivo. 2018.

DVORANEN, E.C.; OLIVEIRA JR., R.S., CONSTANTIN, J., CAVALIERI, S.D.; BLAINSKI, E. Nodulação e crescimento de variedades de soja RR sob aplicação de glyphosate, fluazifop-p-butyl e fomesafen. Planta Daninha, v.26, n.3, p.619625, 2008. http://dx.doi.org/10.1590/5010083582008000300018

FENG, P.C.C.; RYERSE, J.S.; JONES, C.R.; SAMMONS, R.D. Analysis of surfactant leaf damage using microscopy and its relation to glyphosate or deuterium oxide uptake in velvetleaf (Abutilon theophrasti). Pesticide Sci., v. 55, n.3, p.385-386, 1999. https://doi.org/10.1002/(SICI)10969063(199903)55:3\%3C385::AIDPS921\%3E3.0.CO;2-9

FREITAS, G. A.; WEBER, F.; SANTOS, A. C. M.; SILVA CARNEIRO, J. S.; SILVA, R. R. Fertiactyl pós na redução da fitotoxidez do herbicida Roundup Ready na cultura da soja. Revista em Agronegócio e Meio Ambiente, v.11, n.1, p.99116, 2018. https://doi.org/10.17765/21769168.2018v11n1p99-116

HETHERINGTON, P.R.; REYNOLDS, T.L.; MARSHALL, G.; KIRKWOOD, R.C. The absorption, translocation and distribution of the herbicide glyphosate in maize expressing the CP-4 
transgene. J. Exp. Bot., v.50, p.1567-1576, 1999. https://doi.org/10.1093/iexbot/50.339.1567

JUNIOR, E. B.; ROSSIELLO, R. O. P.; SILVA, R. V. M. M.; RIBEIRO, R. C.; MORENZ, M. J. F. A new chlorophyll meter to estimate chlorophyll contents in leaves of Tifton 85 bermudagrass. Ciência Rural, v. 42, n. 12, p. 2242-2245, 2012. http://dx.doi.org/10.1590/S0103$\underline{84782012005000109}$

KRENCHINSKI, F.H.; ALBRECHT, L.P.; ALBRECHT, A.J.P.; CESCO, V. J.S.; RODRIGUES, D.M.; PORTZ, R.L.; ZOBIOLE, H. Glyphosate affects chlorophyll, photosynthesis and water use of four Intacta RR2 soybean cultivars. Acta Physiologiae Plantarum, v.39, n.2, p.1-13, 2017. https://doi.org/10.1007/s11738-017-2358-0

MEROTTO, A.JR.; WAGNER, J.; MENEGUZZI, C. Efeitos do herbicida glifosato e da aplicação foliar de micronutrientes em soja transgênica. Bioscience Journal, v. 31, n. 2, p. 499-508, 2015. https://doi.org/10.14393/BJ-v31n2a2015-22307

SANTOS, A.A.M.; SOUZA, M.A.S.; FREITAS, G.A.; SILVA, P.S.S.; SILVA, R.R. Substância húmica na redução da fitotoxidade dos herbicidas Roundup Ready + Lactofen na cultura da soja. Revista Tecnologia \& Ciência Agropecuária, v. 9, n. 3, p. 35-41, 2015.

SERRA, A. P.; MARCHETTI, M. E.; CANDIDO, A. C. S.; DIAS, A. C. R.; CHRISTOFFOLETI, P. J. Influência do glifosato na eficiência nutricional do nitrogênio, manganês, ferro, cobre e zinco em soja resistente ao glifosato. Ciência Rural, v. 41, n.1, 2011. https://doi.org/10.1590/S010384782011000100013

ZOBIOLE, L. H. S.; OLIVEIRA JR., R. S.; CONSTANTIN, J.; BIFFE, D. F. Prevenção de injúrias causadas por glyphosate em soja RR por meio do uso de aminoácido. Planta Daninha, v.29, n.1, p.195-205, 2011. http://dx.doi.org/10.1590/S0100-

83582011000100022

ZOBIOLE, L. H. S.; OLIVEIRA JR., R. S.; KREMER, R. J.; CONSTANTIN, J.; BONATO, C. M.; MUNIZ, A. S. Water use efficiency and photosynthesis of glyphosate-resistant soybean as affected by glyphosate. Pesticide Biochemistry and
Physiology, v.97, p.182-193, 2010. https://doi.org/10.1016/i.pestbp.2010.01.004

ZOBIOLE, L.H.S.; OLIVEIRA JUNIOR, R.S.; HUBER, D.M.; CONSTANTIN, J.; CASTRO, C.; OLIVEIRA, F.A.; OLIVEIRA JUNIOR, A. Glyphosate reduces shoot concentration of mineral nutrients in glyphosate resistant soybeans. Plant and Soil, v.328, n.1, p.57-69, 2009. https://doi.org/10.1007/s11104-009-0081-3.

VELINI, D. E.; OSIPE, R.; GAZZIERO, D. L. P. Procedimentos para instalação, avaliação e análise de experimentos com herbicidas. Londrina, PR: SBCPD, 1995. 